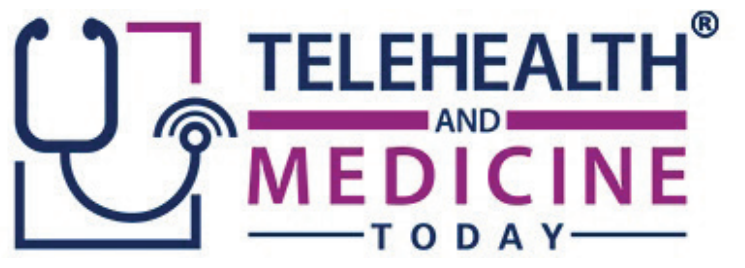

\title{
Telerehabilitation: An Overview
}

Krishnan Ganapathy, M Ch Neurosurgery, FACS, FICS, FAMS, PhD ๑

Affiliations: Apollo Telemedicine Networking Foundation, Chennai, Tamil Nadu, India

Corresponding Author: Krishnan Ganapathy, Email: drganapathy@apollohospitals.com

Keywords: India; Rehabilitation; Telehealth; Telemedicine; Telerehabilitation.

Section: Opinion/Perspective/Point of View

Rehabilitation is a major component of health sciences, and is the process of restoring an incapacitated individual to a normal life through training and therapy. Globally, 2.4 billion people may currently require rehabilitation. In 60 to $70 \%$ of countries, existing rehabilitation services have been disrupted due to the coronavirus disease 2019 (COVID-19) pandemic. Even after lockdowns and with vaccinations, some form of physical distancing is likely to be part of the new normal. Concurrently, there is an exponential growth of telehealth. This global overview will demonstrate that telerehabilitation (TR) is likely to be a distinct stand-alone subspecialty of telehealth. Details of setting up TR, methods, and components are discussed, and clinical indications, limitations, advantages, disadvantages, challenges, and barriers to implementation and technological advances in TR are highlighted followed by an in-depth study of the literature from India.
The author has deployed telehealth in India for the last 21 years $^{1-5}$ in specialties such as: noncommunicable diseases (NCDs), ${ }^{6}$ mobile health, ${ }^{7}$ hospital on wheels, ${ }^{8}$ neurosciences,${ }^{9-15}$ telehealth though public-private partnerships (PPP), ${ }^{16,17}$ tele-emergency services, ${ }^{18}$ artificial intelligence (AI), ${ }^{19}$ space medicine, ${ }^{20,21}$ coronavirus disease (COVID)-related telehealth, ${ }^{22,23}$ telegenomics, ${ }^{24}$ and telerehabilitation (TR). ${ }^{25}$

\section{REHABILITATION SERVICES}

Rehabilitation services help maintain, restore, or improve skills for activities of daily living (ADL) which may have been impaired or lost because of trauma, illness, or temporary or permanent disability. Rehabilitation helps one to be as independent as possible in work, education, and recreation. Improving ADL and pain reduction are primary goals in rehabilitation. Rehabilitation can be provided in inpatient or outpatient hospital settings, private clinics, or community settings, including an individual's 
home. Rehabilitation is highly person-centric, as interventions and approaches selected for each individual depend on individual goals and preferences.

\section{TELEREHABILITATION SERVICES}

Telerehabilitation (TR) is "the delivery of rehabilitation services via Information and Communication Technologies" 26 and includes physiotherapy, speech therapy, and occupational therapy. The coronavirus disease 2019 (COVID-19) pandemic has caused disruption of existing rehabilitation services worldwide, and this reduced access to in-person rehabilitation has resulted in TR growing exponentially. ${ }^{27}$ As physical distancing is critical, rehabilitation services now have to be delivered in innovative ways, yet the correct therapeutic program requires a definite diagnosis. Table 1 discusses the benefits and barriers of TR. Interestingly, face-to-face services still help in socialization, building self-esteem, direct learning, and hands-on training.

Support to ensure TR services are properly functioning is critical when deploying technology, so patient-centric devices should be compatible with the software and hardware used.
Beneficiaries may have impairments of fine/ gross motor skills, cognition, speech, language, vision, or hearing; therefore user-friendly technology that is simple, intuitive, and requires low physical effort makes TR more effective. Telerehabilitation services include: evaluation, assessment, monitoring, intervention, and coaching, and can be deployed in clinics, homes, schools, and community-based sites. ${ }^{28}$ A Fortune Business Insights Report, "Telerehabilitation Market Size, Share and COVID-19 Impact Analysis," estimated a market value of US $\$ 3.32$ billion in $2019 .{ }^{29}$ The compounded annual growth rate (CAGR) of $13.4 \%$ could lead to a market of US $\$ 9.13$ billion by $2027 .{ }^{30}$

\section{METHODS AND COMPONENTS OF TELEREHABILITATION}

Telerehabilitation includes physical, motor, occupational, and speech-language therapy (SLT), deployment of virtual reality, tele-robotic therapy, and use of video games. Webcams, videoconferencing tools, remote evaluation of pre-recorded videos and images, telephonic assessment, and management services are also included. Machines that interface with robotic arms, robotic legs, data gloves, and smart glasses in a $3 \mathrm{D}$ environment allow for a greater sense of

Table 1. Advantages and barriers of telerehabilitation

\begin{tabular}{|l|l|}
\hline $\begin{array}{l}\text { Advantages of TR } \\
\text { Access to high-quality, cost-effective care, reduced travel } \\
\text { and waiting time }\end{array}$ & $\begin{array}{l}\text { Limited computer literacy, unreliable } \\
\text { internet connection }\end{array}$ \\
\hline Exercising from comfort of one's home & Language barrier \\
\hline $\begin{array}{l}\text { Ability to work on one's recovery irrespective of time } \\
\text { schedule of healthcare professionals }\end{array}$ & $\begin{array}{l}\text { Inability to perform an actual physical } \\
\text { assessment }\end{array}$ \\
\hline $\begin{array}{l}\text { Improved quality of exercise instruction is possible as } \\
\text { instructions are available for repeated review on video format }\end{array}$ & Patient privacy \\
\hline $\begin{array}{l}\text { Participants enthusiastic about TR as they could be in } \\
\text { continuous contact with their therapist }{ }^{31}\end{array}$ & Safety concerns \\
\hline
\end{tabular}

TR, telerehabilitation. 
immersion. Visualization using a video catalog of preloaded exercises and the creation of new ones maximize personalization and customization of TR programs.

\section{TELEREHABILITATION SETTING}

For TR to be beneficial, adequate lighting with no background noise or interruptions is imperative. Professional clinical attire is recommended for the therapist. The virtual visit is initiated with an informed consent, followed by ensuring availability of adequate audio-visual facilities. The therapist facilitates the technical set-up for a remote clinical examination, and will need reliable internet, computer, headset, speakers, and microphone. Familiarity with the virtual platform, follow-up appointment scheduling, and training modules is essential. Table 2 discusses the issues with introducing TR to clients.

\section{CLINICAL INDICATIONS FOR TELEREHABILITATION}

- Musculoskeletal disorders, low back pain, spondylosis, osteoarthritis, neck pain, frozen shoulder, post joint replacement.

- Stroke, neuro-trauma, neuro-degenerative disorders, cerebral palsy, post TB meningitis, neuro-muscular disorders, demyelinating diseases, Guillain-Barre syndrome, and Duchenne muscular dystrophy.
- Chronic obstructive pulmonary disorder (COPD).

- Post-ICU and post-COVID conditions.

- Cardiovascular disorders, visual, hearing, developmental, swallowing disorders, speech/voice and cognitive dysfunction.

Virtual assessments for pain, swelling, range of motion, muscle strength, balance, gait, and functional assessment are similar to face-to-face assessments. Telerehabilitation provides personalized high-quality musculoskeletal physiotherapy. Remote muscle strengthening exercises reduce pain, and improve physical functions and quality of life (QoL). A secondary benefit is reduced hospitalization and crowding in physiotherapy departments.

\section{CASE REPORTS}

Telerehabilitation has been used in remote management of diplopia secondary to multiple sclerosis. Cawthorne-Cooksey exercises were taught remotely for better management of eye movements and vision, improving QoL. ${ }^{32}$ Telerehabilitation achieved rehabilitation goals in just four sessions in management of frozen shoulder, ${ }^{33}$ and has been used following total knee and hip arthroplasty; there is limited evidence for successful use of TR in upper limb conditions. ${ }^{34}$ In a report, 69 boys with Duchenne muscular dystrophy and their caregivers, were

Table 2. Challenges and limitations in introducing telerehabilitation

Challenges Limitations

Availability of dependable power, network and Virtual communications with healthcare providers bandwidth could be considered impersonal

Suboptimal lighting, poor audibility, call drop, lag during conversation Lack of physical space at home to properly exercise Difficulty in remote troubleshooting and rest

Shortage of multimedia devices, insufficient training, licensing, liability, and malpractice issues

Elderly may require repeated instructions Therapists need to see the whole person on a screen, which is often difficult. Family members may find supervising home-based activities difficult 
exposed to online workshops. The online motor assessment tool consisted of six motor tests. Videos showing exercises were displayed 132 times within a month. Online videos/instructions/ video guidelines were more acceptable than live workshops. ${ }^{35}$ Online interdisciplinary pain rehabilitation and TR for spinal conditions during the COVID-19 pandemic has been described. ${ }^{36,37}$ Klaic et al. opine that computer literacy and computer anxiety are significant predictors of an individual's likelihood to use teleneurorehabilitation (TNR). ${ }^{38}$ Dementia best practices were extended by increasing the reach of specialists to various locations, including patients' homes. While caregivers' psychosocial concerns are addressed, impact on patients and implications for rehabilitation remain unclear. ${ }^{39}$

\section{TELEREHABILITATION FOR MUSCULOSKELETAL CONDITIONS}

Musculoskeletal disorders (MSDs) are the second most common cause of chronic pain and physical disabilities. Remote physiotherapy assessments include: evaluation of pain, swelling, range of motion, muscle strength, balance, gait, and functional assessment. Telerehabilitation has been studied in MSDs for low back pain, lumbar stenosis, osteoarthritis, and neck pain. Grona et al. report using Skype to implement TR in 22 elderly individuals with MSDs. ${ }^{40}$ An objective, valid, and reliable physiotherapy assessment is a key component in diagnosing and treating MSDs remotely. ${ }^{41}$ Benefits of TR include reduced hospitalization and reduced crowding in outpatient physical therapy departments. Simultaneously, there was improvement in QoL, health outcomes, and return to work. ${ }^{42}$

\section{TELEREHABILITATION FOR STROKE PATIENTS}

A systematic Cochrane Database review of 22 trials involving 1,937 patients on the use of TR found moderate-quality evidence that there was no difference in ADL between people who received a post-hospital TR intervention and those who received the usual care. Significantly different outcomes between the groups were not found, suggesting that TR is not inferior. ${ }^{43}$ Tchero et al. report no differences in recovery amongst stroke patients who received TR and those who received conventional physiotherapy. ${ }^{44}$ In another randomized, assessor-blinded, non-inferiority clinical trial of the motor status of 124 stroke patients, TR and the face-to-face group had similar outcomes. Activity-based training produced substantial gains in arm motor function in both groups. ${ }^{45}$ Delivery, management, and coordination of nursing care services using telecommunications is useful in post-stroke management; however, quality of evidence on use of TR in post-stroke care remains low. ${ }^{46}$

\section{TELEREHABILITATION FOR PULMONARY DISEASES}

The COPD patients can exercise at home, while being monitored from tertiary care centers. Hospital-based pulmonary rehabilitation is normally the first-line of management as it reduces breathlessness and improves exercise tolerance and health-related QoL. In a 2020 publication, Jácome et al. stress the importance of global pulmonary TR. ${ }^{47}$ Home-based pulmonary rehabilitation reduces dyspnea, fatigue, and depression. Functional capacity and sleep are improved, resulting in a better QoL. Home-based pulmonary rehabilitation is simple, inexpensive, convenient, and requires less expertise, while reducing caregiver burden and risk of exposure to infections during travel or institutional stay. Accelerometers and pedometers combined with real-time videos and GPS provide step counts, physical activity, and energy expenditure in COPD patients. Step count and physical activity compliance correlate with mortality and QoL. Real-time monitoring of dyspnea, talk test, walk 
distance, energy expenditure, falls, chest pain, leg fatigue, and functional capacity are measured and archived. The TR network components are: a patient workstation, therapist workstation, and an internet speed of 5 to $10 \mathrm{Mbps} / \mathrm{seconds}$ for streaming videos. A supervised pulmonary rehabilitation unit monitors intensity of exercise, O2 saturation, heart rate, and blood pressure. Adverse events are observed and counselling is given. Exercise adherence is monitored by evaluating the number of sessions attended, and exercise duration, intensity, and frequency. In one study, $79 \%$ of 222 healthcare practitioners working in pulmonary rehabilitation intended to use TR. ${ }^{48}$

\section{TELEREHABILITATION FOR}

\section{CARDIOVASCULAR DISEASE}

An example of TR applied to cardiovascular diseases is the SAPHIRE system. It consists of a bicycle with a touch screen and wireless sensors to check electrocardiogram (ECG), blood pressure, and $\mathrm{O} 2$ saturation in real time. Hospital-based supervising staff connect remotely to a patient's computer touch screen to customize exercises based on a previous exercise stress test. Exercises can be stopped if abnormal values are detected. The machine could interface with robotic arms, robotic legs, data gloves, and smart glasses. Such smart devices used in a $3 \mathrm{D}$ environment allow for a greater sense of immersion in the virtual environment. ${ }^{49}$

\section{TELEREHABILITATION FOR} SWALLOWING DIFFICULTIES

There has been considerable research into the assessment and treatment of dysphagia via TR, including cost analyses, leading to establishment of sustainable TR services. In one study, a sophisticated TR application for assessment of swallowing using a real-time video fluoroscopic examination was done via the internet. ${ }^{50}$
The system enabled the capture and display of images in almost real time.

\section{TELEREHABILITATION FOR CHILDREN}

Telerehabilitation for children requires adequate floor space for demonstrations of gross motor skills, including sitting, creeping, walking, running, jumping, and skipping. Technical preparation for the virtual visit is essential as is close interaction with parents. ${ }^{51}$

\section{TELEPHYSIOTHERAPY}

A customized telephysiotherapy program is made by the physiotherapist who designs the exercise schedule for the patient to execute remotely to treat the cause as well as the symptoms. Evaluation and re-evaluation are done remotely, and licensure concerns and insurance coverage need to be addressed. Details of the exercise program are provided through pre-recorded videos, accessed by mobile phone, tablet, computer, or video calls. The physiotherapist monitors progress during each session in real time or immediately after. Telephysiotherapy ensures continuity of rehabilitation even after discharge from a hospital, and helps all patients receive equal access to rehabilitation services. Individuals with disabilities and chronic illness including the elderly benefit from these services. ${ }^{52}$

Suspension of non-essential services during the COVID-19 pandemic worsened pain and disability amongst patients. Physiotherapists were also affected financially. Traditional physical therapy involves physical touch used to guide, direct, and facilitate movement. This human factor may be reduced in telephysiotherapy. Incorporating 3D virtual reality systems with complex sensors can help address this. ${ }^{53}$ Telephysiotherapy services have developed rapidly with the potential to be a cost-effective alternative, particularly for those inclined to use technology. ${ }^{54}$ 


\section{NECESSITY FOR REHABILITATION IN INDIA}

In India, the market for geriatric rehabilitation alone is high. India has over 100 million citizens over 65 years of age. The projection for 2025 is 158 million people, and for 2050 is 323 million, $18 \%$ of the projected population. ${ }^{55}$ Half of Indians over age 80 have a fall each year. A report from the Confederation of Indian Industries (CII) showed that $5.5 \%$ of seniors stayed at home. ${ }^{56} \mathrm{~A}$ survey by HelpAge revealed that $6 \%$ of seniors live alone, and that $90 \%$ of elderly internet users use social media to connect with family and friends. Seniors now constitute $7 \%$ of the global population, but are expected to reach $34 \%$ by 2095 . With $15 \%$ of the global population having some disability, ${ }^{57} \mathrm{TR}$ is here to stay.

\section{TELEREHABILITATION IN INDIA}

Of the 504 million active internet users in India, $70 \%$ access the internet daily mostly using mobile phones. Interestingly, communication technology is growing faster in rural than in urban areas. ${ }^{58} \mathrm{In}$ 2020, 500 million Indians were using smartphones and $77 \%$ were accessing broadband services using smartphones. ${ }^{59}$ Publications on telephysiotherapy from India stress that this is a clinical application of consultative, diagnostic, preventive, and therapeutic services via two-way interactive technology. ${ }^{60}$ Telephysiotherapy includes diagnosis, surveillance, care, guidance, support, and counselling. ${ }^{61}$ Limited health resources lead to increasing deployment of technology. Barriers to growth and development of TR in India include: technology, literacy, education, inadequate power supply, network issues, and shortage of multimedia devices. ${ }^{62,63}$ Jayarajan et al. point out that individuals may have difficulty using devices and software effectively or access may be difficult as multiple users could need to use the same device. ${ }^{64}$ Family members may find supervising home-based activities difficult. Better bandwidth and video quality improve assessment accuracy, especially when scales that assess negative symptoms or that depend on non-verbal cues are used. Current guidelines in India do not refer to IQ assessment or specific learning disability tests for remote therapy. ${ }^{65}$ The visually challenged require a longer interaction, counselling, education, and one-to-one rehabilitation training. Senjam et al. report on successful TR for the visually impaired during the COVID-19 lockdown. ${ }^{66}$

In another publication, the Institute for Vision Rehabilitation at LV Prasad Eye Institute, Hyderabad, South India, used a TR approach. ${ }^{67}$ In the study, 250 volunteers helped with content development, voice recording, fundraising, translation of educational materials, and other measures. The feasibility and utility of TNR services in India in a quaternary center was described.$^{68}$ The multidisciplinary team utilized TNR for stroke, cerebral palsy, sequelae of tuberculous meningitis, and neuromuscular disorders.

The National Institute of Mental Health and Neuro-Sciences delivered tele-mental- health services during the COVID-19 crisis to ensure continuity of care during the lockdown period. Telephone and videoconferencing were used, along with ePrescriptions, home delivery of drugs, referrals for treatment of medical comorbidities, financial support, and liaison with employers. Anushree et al. emphasize the need of looking into minute technical details, to ensure "customer delight." ${ }^{69}$ Usefulness of TR in COPD is still not sufficiently recognized. ${ }^{70}$

Tele-neurorehabilitation in the management of Parkinson's disease has been described from India. ${ }^{71} \mathrm{~A}$ report on 22 senior citizens from four community centers in Delhi showed that homebased TR could be used for follow-up care. ${ }^{72}$ Telepractice in speech-language pathology commenced in 2009 at the All India Institute 
of Speech and Hearing with launch of a specialized center for rehabilitation and education. ${ }^{73}$ In 2012, a case report revealed improvement in expression, repetition, naming, and memory in a patient with Broca's aphasia after remote speech therapy. ${ }^{74}$ Only a few speechlanguage pathologists in India provide TR. ${ }^{75} \mathrm{~A}$ publication from the Tele-Center for Persons with Communication Disorders, highlights advantages of telehealth from a client/caregiver perspective. ${ }^{76}$

The clinical effectiveness of TR for various MSDs during the pandemic has been reported from central India. ${ }^{77}$ There was significant pain reduction and betterment of patient-reported functional goals. Back pain (45.16\%) was the most common musculoskeletal problem encountered, and $68 \%$ of the patients achieved more than $80 \%$ functional goals with remote guidance. With the imminent availability of Bharat Net for rural broadband, TR will be possible even for rural India. ${ }^{78}$

\section{ILLUSTRATIONS OF TR: THE GLOBAL SCENARIO}

Country-specific challenges in implementing TR are discussed below. A report from the Philippines discusses telehealth acceptance, facilitators, barriers, and satisfaction. ${ }^{79}$ Slow internet speed, legal concerns, and skepticism were common. A paper from Italy reported on remote motor and cognitive rehabilitation programs applied to neurological pathologies. ${ }^{80}$ No TR is available in Saudi Arabia, ${ }^{81}$ yet a survey showed that half of the rehabilitation care providers considered TR as an important service delivery method, though they were not users. The United States Department of Veterans Affairs provides remote annual physical exams, monitoring, and consultation for veterans with spinal cord injuries ${ }^{82}$ Several State Medicaid programs use telecommunications to connect rural practitioners with specialty therapists. A few school districts in Oklahoma and Hawaii offer school-based rehabilitation therapy using therapy assistants who are directed by a remote therapist. The National Rehabilitation Hospital in Washington, DC and Sister Kenny Rehabilitation Institute in Minnesota provide assessment and evaluations to patients living in Guam and American Samoa for post-stroke, post-polio, autism, and wheelchair fitting. A study in Nigeria revealed that physiotherapy students have moderate awareness and high expectation for future TR applications. The authors attribute the expectations to familiarity with technology as respondents were "digital natives." 83

\section{TECHNOLOGY}

Technology plays a major role in TR. However deployment of technology should be contextual, catering to usage by all, must incorporate user friendliness, flexibility, simplicity, and intuitiveness. There should be a high tolerance for error, yet physical effort required should be low. Technologies available include: text, audio, visual, virtual reality, web-based, and wireless integrated systems. The selection of a remote rehabilitation system involves multiple factors. Technology should be cost effective, with adequate support, suited to specific purposes. Complex technology (multiple components, settings and/or connections) may be associated with higher cost and a higher learning curve, leading to reduced use.

Virtual reality allows for the development of 3D virtual environments with motion technology. In rich web applications, sensors and body monitoring are done using cloud-based software using haptic technology, virtual reality, mobile apps, and gaming programs to monitor outcomes and deliver instructions and solutions. ${ }^{84}$ The TR-enabled devices help therapists monitor patients remotely, using applications installed on a tablet or smartphone along with customized smart gloves and splints. ${ }^{85}$ Wireless sensors on 
a smart glove, track wrist and finger movements and stream the data to a receiver. The app allows engagement through instructional material (video, image, text) to record patient performance. Patients can practice independently without a therapist's online presence. In this case, a receiver plugs into the software, which plots and interprets the sensor data, providing advanced statistical data analysis. A TR platform has an exercise kit with biomechanical sensors allowing the software to analyze range of motion, speed, and muscle strength during exercises. Feedback is sent to the patient. ${ }^{86}$ Smartphone apps enable therapeutic interventions, remote monitoring of progress, education, consultation, and training. A number of apps, interactive tools, and podcasts cater to various healthcare conditions. ${ }^{87}$ Computer-assisted cognitive rehabilitation systems and serious games are available. Sensors and actuators compensate for the absence of a therapist's eyes and hands. Oliver et al. propose an ambient intelligence environment for cognitive rehabilitation at home, combining physical and cognitive activities using a Fuzzy Inference System, which has a remote monitoring tool so the therapist can remotely supervise patient exercises. $^{88}$

Virtual reality can recreate realistic environments in which patients may operate. Wearable sensors allow quantitative monitoring of a patient's performance, while signal processing assists in prediction of long-term dynamics of patient recovery. ${ }^{89}$ Acceptance of VR implies familiarity and confidence in the technology, which can mean prompt technical assistance in case of a malfunction. Side effects related to VR include motion sickness syndrome, and equipment costs could be significant. Rapidly evolving technologies are making additional tools available for rehabilitation. Clinicians can now immerse their patients in different virtual worlds to reduce pain and anxiety, and to encourage them to move by playing games. Performance measures, not easily detectable by the naked eye, can now be quantified. Technological solutions for rehabilitation need to be dependable. ${ }^{90}$ Advancements in software, biosensors, and communication technology has allowed clinicians to administer various TR-based applications.

\section{TELEREHABILITATION: FUTURE PERSPECTIVES}

Telerehabilitation will eventually be integrated with smart homes in smart cities. Functional monitoring with bed sensors, activity/motion sensors, and gait monitors will be a reality. This will be followed by creating a connected home with pressure-sensing floors, smart furniture, and medical sensors. Integrating smart rehabilitation appliances needs to be contextual. Assistive robots, powered wheelchairs, prosthetic limb controls, home automation systems, and home AI chat-bot companions will add value, providing "smarter care." This will include encouraging activities and contacting caregivers/children in emergencies. Internet of Medical Things (IoMT) with cloud-based technology will result in a continuum of healthcare leading to radical improvement as it is known that aging in place leads to better health outcomes.

\section{CONCLUSIONS}

Understanding who will use TR, and how it will help achieve customized, well-defined goals is critical. The beneficiaries' goals alone matter, and TR is only one tool to achieve them. The healthcare provider using TR should take time to understand the users' needs, never forgetting that what is simple for digital natives can be a barrier for an octogenarian. Telerehabilitation should solve problems, not become a solution searching for a problem. The global pandemic has helped to ensure that TR is here to stay. 
Acknowledgments: The author thanks Ms.

Lakshmi for providing secretarial assistance.

Conflicts of Interest: There is no conflict of interest.

Funding Statement: No funding was received to support this work.

\section{REFERENCES}

1. Ganapathy K. Telemedicine in India: Personal Reminiscences from 1996. Tamilnadu Chapter of Telemedicine Society of India e-Newsletter Sep Issue. 2020 Available from: https://tsitn.org/tsi-enewsletter-sep2020/ [cited 1 Oct 2021].

2. Ganapathy K. Official website. 2021. Available from: http://drkganapathy.com/ [cited 1 Oct 2021].

3. Ganapathy K, Aditi R. Healthcare for rural India: Is telemedicine the solution? J eHealth Technol Applic. 2007;5:203-7.

4. Ganapathy K. Telehealth for one sixth of humankind making it happen: The Apollo Story. In: Jordanova M, Lievens F, eds. Global telemedicine and ehealth updates: Knowledge resources. ISfTeH Belgium. 2015;8:128-33.

5. Ganapathy K. Interview. Eur Med J. 2020. Available from: https://www.emjreviews. com/innovations/article/interview-drkrishnan-ganapathy/ [cited 1 Oct 2021].

6. Ganapathy K, Nukala L, Premanand S, Tamilmaran P, Aggarwal P, Saksena $\mathrm{S}$, et al. Telemedicine in camp mode while screening for noncommunicable diseases: A preliminary report from India. Telemed J E Health. 2020;26:42-50. https://doi.org/10.1089/tmj.2018.0300

7. Ganapathy K, Kanwar V, Bhatnagar T, Uthayakumaran N. m-Health: A critical analysis of awareness, perception, and attitude of healthcare among providers in Himachal Pradesh, North India. Telemed J E Health. 2016;22:675-88. https://doi. org/10.1089/tmj.2015.0198
8. Xixi L, Rai A, Ganapathy K. Designing cost-effective telemedicine camps for underprivileged individuals in less developed countries: A decomposed affordanceeffectivity framework. J Assoc Inform Sys. 2020. Available from: https://en.wikipedia. org/wiki/Telerehabilitation [cited 1 Oct 2021].

9. Ganapathy K. Deployment of telemedicine in neurosciences: The good and the evil - A balanced approach. Neurol India. 2018;66:1852-3. https://doi. org/10.4103/0028-3886.246295

10. Ganapathy K. Telemedicine and neurosciences. Neurol India. 2018;66:642-51. https://doi.org/10.4103/0028-3886.232346

11. Ganapathy K. Distribution of neurologists and neurosurgeons in India and its relevance to the adoption of telemedicine. Neurol India. 2015;63:142-54. https://doi. org/10.4103/0028-3886.156274

12. Ganapathy K. Telemedicine and neurosciences in developing countries. Surg Neurol. 2002;58:388-95. https://doi. org/10.1016/S0090-3019(02)00924-2

13. Ganapathy K. Telemedicine \& neurosciences - A review. J Clin Neurosci. 2005;12:851-62. https://doi.org/10.1016/j. jocn.2005.07.004

14. Haranath SP, Ganapathy K, Reddy KS, Deepak KS. eNeuroIntensive care in India: The need of the hour. Neurol India. 2021;69:245-51. https://doi. org/10.4103/0028-3886.314591

15. Ganapathy K. Telemedicine: An integral part of clinical neurosciences. Neurol India. 2021;69:352-3. https://doi. org/10.4103/0028-3886.314545

16. Ganapathy K, Chawdhry V, Premanand S, Sarma A, Chandralekha J, Kumar KY, et al. Telemedicine in the Himalayas: Operational challenges - A preliminary report. Telemed J E Health. 2016;22:821-35. https://doi. org/10.1089/tmj.2015.0249

17. Ganapathy K, Das S, Reddy S, Thaploo V, Nazneen A, Kosuru A, et al. Digital health care in public private partnership mode. Telemed J E Health. 2021; 27(10). https:// doi.org/10.1089/tmj.2020.0499 
18. Ganapathy K, Alagappan D, Rajakumar H, Dhanapal B, Rama Subbu G, Nukala $\mathrm{L}$, et al. Tele-emergency services in the Himalayas. Telemed J E Health. 2019;25:380-90. https://doi.org/10.1089/ tmj.2018.0027

19. Ganapathy K. Artificial intelligence and healthcare regulatory and legal concerns. Telehealth Med Today. 2021;6(2). https:// doi.org/10.30953/tmt.v6.252

20. Ganapathy K. Space medicine: The ultimate in remote health care. Telehealth Med Today. 2020;5(2). https://doi.org/10.30953/tmt. v5.178

21. Ganapathy K. Extra-terrestrial neurosciences. Neurol India. 2019;67:165-6. https://doi. org/10.4103/0028-3886.259118

22. Ganapathy K. Telemedicine and neurological practice in the COVID-19 Era. Neurol India. 2020;68:555-9. https://doi. org/10.4103/0028-3886.288994

23. Ganapathy K. Telemedicine and Covid 19. Apollo Med. 2020;17:205-8. https://doi. org/10.4103/am.am_84_20

24. Ganapathy K. Telegenomics: Relevance in India. Apollo Med. 2021;18:122-6. https:// doi.org/10.4103/am.am_26_21

25. Ganapathy K. Telerehabilitation: The time has come. Keynote address. Indian Association of Physical Medicine and Rehabilitation, 27 June 2021. Available from: https://youtu.be/RNEIZqc3w5A [cited 1 Oct 2021].

26. Brennan D, Tindall L, Theodoros D, Brown, J, Campbell M, Christiana D, et al. 2010. A blueprint for telerehabilitation guidelines. Int J Telerehabil. 2010;2:31-34. https://doi. org/10.5195/ijt.2010.6063

27. Tenforde AS, Borgstrom H, Polich G, Steere H, Davis IS, Cotton K, et al. Outpatient physical, occupational, and speech therapy synchronous telemedicine: A survey study of patient satisfaction with virtual visits during the COVID-19 pandemic. Am J Phys Med Rehabil. 2020;99:977-81. https://doi. org/10.1097/PHM.0000000000001571

28. Richmond T, Peterson C, Cason J, Billings M, Terrell EA, Lee ACW, et al. American
Telemedicine Association's principles for delivering telerehabilitation services. Int J Telerehabil. 2017;9:63-8. https://doi. org/10.5195/ijt.2017.6232

29. Fortune Business Insights (2020). Market research report on the global telerehabilitation market size, share and Covid-19 impact analysis and regional forecast, 20202027. Available from: https://www. fortunebusinessinsights.com/telerehabilitationmarket-103112 [cited 1 Oct 2021].

30. Fortune Business Insights (2021). Telerehabilitation Market Size 2021. Available from: https://www.globenewswire. com/news-release/2021/04/07/2205951/0/ en/Telerehabilitation-Market-Size-2021-ToExhibit-13-4-CAGR-and-Hit-USD-9-13Billion-by-2027.html [cited 1 Oct 2021].

31. Jansen-Kosterink S, Dekker-van Weering M, van Velsen L. Patient acceptance of a telemedicine service for rehabilitation care: A focus group study. Int J Med Inform. 2019;125:22-9. https://doi.org/10.1016/j. ijmedinf.2019.01.011

32. Dogru-Huzmeli E, Duman T, Cakmak AI, Aksay U. Can diplopia complaint be reduced by telerehabilitation in multiple sclerosis patient during the pandemic? A case report. Neurol Sci. 2021;24:1-4. https://doi. org/10.1007/s10072-021-05194-2

33. Neo JH, Teo ST, Lee CL, Cai CC. Telerehabilitation in the treatment of frozen shoulder: A case report. Int J Telerehabilitation. 2019;11:3-8. https://doi. org/10.5195/ijt.2019.6288

34. Pastora-Bernal JM, Martín-Valero R, Barón-López FJ, Estebanez-Pérez MJ. Evidence of benefit of telerehabitation after orthopedic surgery: A systematic review. J Med Internet Res. 2017;19:e142. https://doi. org/10.2196/jmir.6836

35. Sobierajska-Rek A, Mański Ł, JabłońskaBrudło J, Śledzińska K, Ucińska A, Wierzba J. Establishing a telerehabilitation program for patients with Duchenne muscular dystrophy in the COVID19 pandemic. Wien Klin Wochenschr. 2021;133:344-50. 
36. Baadjou VA, Hollander MD, Meulenbroek TV, Verbunt JA, Timmers I. Clinicians' Initial experiences of transition to online interdisciplinary pain rehabilitation during the Covid-19 pandemic. J Rehabil Med Clin Commun. 2020;3:1000036. https://doi. org/10.2340/20030711-1000036

37. Bhuva S, Lankford C, Patel N, Haddas R. Implementation and patient satisfaction of telemedicine in spine physical medicine and rehabilitation patients during the COVID19 shutdown. Am J Phys Med Rehabil. 2020;99:1079-85. https://doi.org/10.1097/ PHM.0000000000001600

38. Klaic M, Galea MP. Using the Technology Acceptance Model to identify factors that predict likelihood to adopt teleneurorehabilitation. Front Neurol. 2020;11:580832. https://doi.org/10.3389/ fneur.2020.580832

39. Gately ME, Trudeau SA, Moo LR. In-home video telehealth for dementia management: Implications for rehabilitation. Curr Geriatr Rep. 2019;8:239-49. https://doi. org/10.1007/s13670-019-00297-3

40. Grona SL, Bath B, Busch A, Rotter T, Trask C, Harrison E. Use of videoconferencing for physical therapy in people with musculoskeletal conditions:

A systematic review. J Telemed Telecare. 2018;24:341-55. https://doi. org/10.1177/1357633X17700781

41. Mani S, Sharma S, Omar B, Paungmali A, Joseph L. Validity and reliability of Internet-based physiotherapy assessment for musculoskeletal disorders: A systematic review. J Telemed Telecare. 2017;23:379-91. https://doi. org/10.1177/1357633X16642369

42. Kilova K, Kitova T, Kasnakova P. Telemedicine in help of rehabilitation in the conditions of COVID-19. Health Policy Technol. 2021;10:100508. https://doi. org/10.1016/j.hlpt.2021.100508

43. Laver KE, Adey-Wakeling Z, Crotty M, Lannin NA, George S, Sherrington C. Telerehabilitation services for stroke. Cochrane Database Syst
Rev. 2020;1:CD010255. https://doi. org/10.1002/14651858.CD010255.pub3

44. Tchero H, Tabue Teguo M, Lannuzel A, Rusch E. Telerehabilitation for stroke survivors: Systematic review and meta-analysis. J Med Internet Res. 2018;20:e10867. https://doi. org/10.2196/10867

45. Cramer SC, Dodakian L, Le V, See J, Augsburger R, McKenzie A, et al. Efficacy of home-based telerehabilitation vs inclinic therapy for adults after stroke: A randomized clinical trial. JAMA Neurol. 2019;76:1079-87. https://doi.org/10.1001/ jamaneurol.2019.1604

46. Bashir A. Stroke and telerehabilitation: A brief communication. JMIR Rehabil Assist Technol. 2020;7:e18919. https://doi. org/10.2196/18919

47. Jácome C, Marques A, Oliveira A, Rodrigues LV, Sanches I. Pulmonary telerehabilitation: An international call for action. Pulmonology. 2020;26:335-7. https://doi.org/10.1016/j. pulmoe.2020.05.018

48. Almojaibel AA, Munk N, Goodfellow LT, Fisher TF, Miller KK, Comer AR, et al. Health Care practitioners' determinants of telerehabilitation acceptance. Int J Telerehabil. 2020;12:43-50.

49. Peretti A, Amenta F, Tayebati SK, Nittari G, Mahdi SS. Telerehabilitation: Review of the state-of-the-art and areas of application. JMIR Rehabil Assist Technol. 2017;4:e7. https://doi.org/10.2196/rehab.7511

50. Perlman AL, Witthawaskul W. Realtime remote telefluoroscopic assessment of patients with dysphagia. Dysphagia. 2002;17:162-7. https://doi.org/10.1007/ s00455-001-0116-2

51. Rabatin AE, Lynch ME, Severson MC, Brandenburg JE, Driscoll SW. Pediatric telerehabilitation medicine: Making your virtual visits efficient, effective and fun. J Pediatr Rehabil Med. 2020;13:355-70. https://doi.org/10.3233/PRM-200748

52. Alexander M. It's corona calling: Time for telerehabilitation! J Frailty Sarcopenia Falls. 
2020;5:86-8. https://doi.org/10.22540/ JFSF-05-086

53. Saleh A, Raed A, Faizan K, Mazen A, Ahmad A, Msaad A, et al. Knowledge, attitude, and barriers to telerehabilitationbased physical therapy practice in Saudi Arabia. Healthcare. 2020;8:1-10. https:// doi.org/10.3390/healthcare 8040460

54. van Egmond MA, van der Schaaf $M$, Vredeveld T, Vollenbroek-Hutten MMR, van Berge Henegouwen MI, Klinkenbijl JHG, et al. Effectiveness of physiotherapy with telerehabilitation in surgical patients: A systematic review and meta-analysis. Physiotherapy. 2018;104:277-98. https:// doi.org/10.1016/j.physio.2018.04.004

55. Miller TW. Smart advances in healthcare for geriatric patients. Am J Biomed Sci Res. 2019;1:130-1. https://doi.org/10.34297/

AJBSR.2019.01.000526

56. MoneyLife Digital Team (2018). India's ageing population to reach 300 million by 2050 and raising demand for better services for seniors. Available from: https://www.moneylife.in/article/ indias-ageing-population-to-reach-300million-by-2050-and-raising-demand-forbetter-services-for-seniors-report/54140. html [cited 1 Oct 2021].

57. World Health Organization (2011). World Report on Disability 2011. Available from: https://www.who.int/publications/i/ item/9789241564182 [cited 1 Oct 2021].

58. IAMAI (2019). Digital in India 2019 Round 2 Report. Internet and Mobile Association of India (IAMAI) and Nielsen. Available from: https://cms.iamai.in/ Content/ResearchPapers/2286f4d7-424f4bde-be88-6415fe5021d5.pdf [cited 1 Oct 2021].

59. TechInsight (2020). TechArc Report. With 502.2 million Smartphone users, it's time for Smartphone brands to turn towards services in 2020. Available from: https:// techarc.net/techinsight-at-502-2-millionsmartphone-users-its-time-for-smartphonebrands-to-turn-towards-services-in-2020/ [cited 1 Oct 2021].
60. CB Physiotherapy (2021). Does Telephysiotherapy work? Who can benefit from it? Available from: https://cbphysiotherapy.in/blog/doestelephysiotherapy-work-who-can-benefitfrom-it [cited 1 Oct 2021].

61. Jachak SP, Phansopkar PA, Naqvi WM, Kumar K. Great awakening Telerehabilitation in physiotherapy during pandemic and impact of COVID 19. J Evol Med Dent Sci. 2020;9:3387-93. https://doi. org/10.14260/jemds/2020/744

62. Shenoy MP, Shenoy PD. Identifying the challenges and cost-effectiveness of telerehabilitation: A narrative review. J Clin Diagn Res. 2021;12:1-4.

63. Ateeq A, Jahan N, Alam MF, Khanum F. Role of telerehabilitation in musculoskeletal conditions during COVID-19 pandemic. Indian J Pain. 2020;34:217-8.

64. Jayarajan D, Sivakumar T, Torous JB, Thirthalli J. Telerehabilitation in psychiatry. Indian J Psychol Med. 2020;42:57-62. https://doi.org/10.1177/0253717620963202

65. Medical Council of India (2020). Telemedicine practice guidelines. Available from: https://www.mohfw.gov.in/pdf/ Telemedicine.pdf [cited 1 Oct 2021].

66. Senjam SS, Manna S, Vashist P, Gupta V, Varughese S, Tandon R. Tele-rehabilitation for visually challenged students during COVID-19 pandemic: Lesson learned. Indian J Ophthalmol. 2021;69:722-8. https://doi.org/10.4103/ijo.IJO_2527_20

67. Christy B, Keeffe J. Telerehabilitation during COVID-19. Indian J Ophthalmol. 2020;68:1489-90. https://doi.org/10.4103/ ijo.IJO_1197_20

68. Khanna M, Gowda GS, Bagevadi VI, Gupta A, Kulkarni K, S Shyam RP, et al. Feasibility and utility of teleneurorehabilitation service in India: Experience from a quaternary center. $\mathrm{J}$ Neurosci Rural Pract. 2018;9:541-4. https:// doi.org/10.4103/jnrp.jnrp_104_18

69. Anushree N, Kavitha R, Harshal TP. Telerehabilitation in India: Points to ponder. Indian J Physiother Occup 
Ther. 2019;13:18-21. https://doi. org/10.5958/0973-5674.2019.00084.4

70. Bairapareddy KC, Chandrasekaran B, Agarwal U. Telerehabilitation for chronic obstructive pulmonary disease patients: An underrecognized management in tertiary care. Indian J Palliat Care. 2018;24:529-33. https://doi.org/10.4103/IJPC.IJPC_89_18

71. Garg D, Dhamija RK. Teleneurorehabilitation for Parkinson's disease: A panacea for the times to come? Ann Indian Acad Neurol. 2020;23:592-7. https://doi.org/10.4103/aian. AIAN_566_20

72. Nishu T, Ruby A, Jitendra PS. Telerehabilitation as an adjunct service for geri care: Reaching the unreached. Int J Sci Res. 2015;4:332-4.

73. Vrinda R, Reni PS. Telerehabilitation in the field of speech language pathology during pandemic COVID-19 outbreak-an analysis in Kerala. Biosc Biotech Res Comm. 2020;13:2281-8. https://doi.org/10.21786/ bbrc/13.4/99

74. Goswami SP, Bhutada A, Jayachandran $\mathrm{K}$. Telepractice in a person with aphasia. J All India Inst Speech Hearing (JAIISH) 2012;31:159-67.

75. Mohan HS, Anjum A, Rao PK. A survey of telepractice in speech-language pathology and audiology in India. Int J Telerehab. 2017;9:69-80. https://doi.org/10.5195/ ijt.2017.6233

76. Rao S, Prema K, Yashaswini R. Telepractice in speech-language pathology and audiology: Prospects and challenges. J Indian Speech Language Hearing Assoc. 2018;32:67-72. https://doi.org/10.4103/ jisha.JISHA_39_17

77. Sheetal M, Preeti M, Rekha K, Divya S, Ashutosh M, Dhananjay R. Telerehabilitation for musculoskeletal disorders during the COVID-19 pandemic. Int J Physiother Res. 2021;9:3765-72. https://doi.org/10.16965/ijpr.2021.106

78. BharatNet Project (2020). Drishti The Vision Foundation. Available from: https://www. drishtiias.com/daily-updates/daily-newsanalysis/bharatnet-project [cited 1 Oct 2021].
79. Leochico CFD, Espiritu AI, Ignacio SD, Mojica JAP. Challenges to the emergence of telerehabilitation in a developing country: A systematic review. Front Neurol. 2020;11:1007. https://doi.org/10.3389/ fneur.2020.01007

80. Maresca G, Maggio MG, De Luca R, Manuli A, Tonin P, Pignolo L, et al. Teleneuro-rehabilitation in Italy: State of the art and future perspectives. Front Neurol. 2020;11:563375. https://doi.org/10.3389/ fneur.2020.563375

81. Qureshi AZ, Ullah S, Aldajani AA, Basson P, AlHabter AM, Ali T, et al. Telerehabilitation guidelines in Saudi Arabia. Telemed J E Health. 2021. https:// doi.org/10.1089/tmj.2020.0355

82. Wikipedia (2021). Telerehabilitation. Available from: https://en.wikipedia.org/ wiki/Telerehabilitation [cited 1 Oct 2021].

83. Mbada CE, Baderinwa TA, Sanuade CT, Ademoyegun Adekola B, Fatoye C, Maikudi L, et al. Awareness, attitude and expectations of physiotherapy students on telerehabilitation. Med Sci Educ. 2021;18:1-10.

84. Prvu Bettger J, Resnik LJ. Telerehabilitation in the age of COVID-19: An opportunity for learning health system research. Phys Ther. 2020;100:1913-6. https://doi.org/10.1093/ $\mathrm{ptj} / \mathrm{pzaa} 151$

85. Choukou A. How the COVID-19 pandemic breaks new ground for in-home telerehabilitation. Active Assisted Living (AAL) Programme, University of Manitoba. 2021. Available from: http://www.aaleurope.eu/pandemic-telerehabilitation/ [cited 1 Oct 2021].

86. DyCare (2021). How to choose the best telerehabilitation platform: 7 key points. Available from: https://www.dycare. $\mathrm{com} /$ products/how-to-choose-the-besttelerehabilitation-platform-7-key-points/ [cited 1 Oct 2021].

87. Physiopedia (2015). Telerehabilitation and Smartphone apps in physiotherapy. Available from: https://www.physio-pedia.com/ 
Telerehabilitation_and_Smartphone_Apps_ in_Physiotherapy [cited 1 Oct 2021].

88. Oliver M, Teruel MA, Molina JP, Romero-Ayuso D, González P. Ambient intelligence environment for home cognitive telerehabilitation. Sensors (Basel) 2018;18:3671. https://doi.org/10.3390/ s18113671

89. Nuara A, Fabbri-Destro M, Scalona E, Lenzi SE, Rizzolatti G, Avanzini P. Telerehabilitation in response to constrained physical distance: An opportunity to rethink neurorehabilitative routines. J Neurol. 2021;15:1-12. https://doi.org/10.1007/ s00415-021-10397-w

90. Krasovsky T, Lubetzky AV, Archambault PS, Wright WG. Will virtual rehabilitation replace clinicians: A contemporary debate about technological versus human obsolescence. J Neuroeng Rehabil. 2020;9;17:163. https://doi.org/10.1186/ s12984-020-00769-0

Copyright Ownership: This is an open access article distributed in accordance with the Creative Commons Attribution Non Commercial (CC BY-NC 4.0) license, which permits others to distribute, adapt, enhance this work non-commercially, and license their derivative works on different terms, provided the original work is properly cited and the use is noncommercial. See: http://creativecommons. org/licenses/by-nc/4.0. 